\title{
Public Health Risk: Public Views on Panic Reporting and Media Framing of the Covid 19 Pandemic
}

\author{
AKPOGHIRAN, Idamah Patrick. Ph.D \\ Department of Mass Communication, Western Delta University, Oghara, Delta State, Nigeria
}

\begin{abstract}
The study examines public views on panic reporting and media framing on the COVID 19 pandemic. Panic is expected during public health risk reporting. Media coverage and the manner of framing of the COVID 19 pandemics earlier created panics and uncertainties among the public. A measuring scale was designed in accordance with the objectives of the study to ascertained respondents views. Through the administration of copies of questionnaire, views of thirty four persons on the subject were ascertained. Results showed that though media framing and coverage of the pandemic news increases public panic, it however reduces the spread of the virus; the public became conscious of the virus. Media framing of the pandemic not only causes fears but also led to panic buying of food items at home. The outbreak of the pandemic exposes government failed health system in Nigeria. The study also showed that the emotional effects as a result of the manner of framing were more harmful than the virus itself. This is because the pandemic news was not carefully managed by the media at the earlier outbreak. Management of news during public health risk or crisis is important for easing panic. It was established that responsible health attitude is most appropriate to ease panics.
\end{abstract}

Keywords: Covid 19; Framing; Media; Pandemic; Panic; Public; Reporting

DOI: $10.7176 / \mathrm{NMMC} / 100-02$

Publication date: January $31^{\text {st }} 2022$

\section{INTRODUCTION}

There are studies on public health risk to show that the mass media have been used as a way of delivering preventive health messages since they have the potential to influence people's behaviour (Brinn, Carson, Esterman, Chang, \& Smith, 2012). The media also served as a major source of information to incite changes in behaviour in the public attending to health news (Viswanath, Ramanadhan, \& Kontos, 2007). Other studies have also shown that the mass media played a leading role in disseminating health news (McCauley; Blake; Meissner; \& Viswanath, 2013) due to the importance of accurate health news reports, and the national need to professionalism in health journalism (Keshvari, Niko; Adibi; \& Shahnazi, 2018) whereby affecting the knowledge and health beliefs of the public (McCombs, 2013). Media attention to health news has been increasing in importance during the last few decades, and thus, media reports can play an important role in defining health issues because the mass media have used to inform individuals regarding diseases within a population (Collinson \& Heffernan, 2014).

A timeline of historical pandemics shows that the more population increased in contacts with different people, chemicals, animals and the ecosystem, the more pandemics would occur. The world had experienced Cholera outbreak, yellow fever occurred in the 1880s, and then, the Russian Flu, the Spanish Flu, the Asian and Hong Kong Flu. Till date there is HIV/AIDS, which started in the early 1981s, Swine Flu (H1N1), there was Severe Acute Respiratory Syndrome (SARS) which, occurred in 2002, then, Ebola occurred in 2014 and the Middle East Respiratory Syndrome (MERS) in 2015 causing fears and deaths among the public. In 2019, the Coronavirus (COVID 19) pandemic occurred. These various diseases affected millions of people all over the entire world causing deaths.

The worst side of these pandemics mentioned is fear. From the start of these global pandemics, fear has been the major cause of deaths than the viruses. It seems that fear was been aggravated by media coverage and the manner of the reportage. Fear, as Wahl-Jorgensen (2020) noted, is an emotion that we frequently experience as individuals, it can also be a shared and social emotion, one which circulates through groups and communities and shapes our reactions to ongoing events. Like other emotions, fear is contagious and can spread quickly causing public panic than the virus itself. For example, it could be assumed that the Ebola outbreak in Nigeria in 2015 that caused public anxiety and panic was attributed to the frequent reports by the media's in a dramatized panic coverage. Also, frequent media reports and from unauthorized social media sources during diseases like the Ebola and Bird Flu outbreak in Nigeria have often led to increased anxiety, stress and panic among the general public. Since contagious diseases are scary, panic has therefore become a contagious disease especially when the media report it as it is.

Panic reporting is also evident in security issues (Akpoghiran \& Otite, 2013), natural disasters, food security, and health security (Tchuenche \& Bauch, 2012; Collinson \& Heffernan, 2014; Wahl-Jorgensen, 2020; Dong \& Zheng, 2020). Panic is an expected emotion during reporting public health risk. Studies have described panic during public health risk reporting as risk communication (WHO, 2009). WHO described risk 
communication as the dissemination of information primarily to the public about health risks and events, such as outbreaks of disease and instructions on how to change behaviour to mitigate those risks. Public health is not a risk-free activity (Suckling; Ferris; \& Price; 2020), it involves media enlightenment campaigns to change behaviour.

The news coverage on these epidemics and pandemics has been overwhelming. For example, the news coverage on Covid 19 pandemic made on the general public to feel dazed and even plunged into anxiety and panic (Dong \& Zheng, 2020). The use of instant-messaging technology, mobile phones and the 'hot' manner the media presented it, makes the news spread faster and exacerbates the anxiety and panic of public. WahlJorgensen (2020) described the media scenario as 'extensive media attention'. As Dong and Zheng noted, the psychological disorder caused by too many news coverage was named as 'headline stress disorder' by Steven Stosny, a psychologist, meaning a high emotional response to endless reports from the news media, such as feeling anxiety and stress. As it were, the continued anxiety or stress may cause physical functional disorders, including palpitation, chest tightness and insomnia, and further progression may lead to physical and mental diseases, such as anxiety disorders, depression disorders, endocrine disorders and hypertension (Batelaan; Seldenrijk; Bot, Balkom; \& Penninx 2016; Liu; Li NA, Li WA; Khan, 2017). World Bank in 2017 report on 'Financing Pandemic Preparedness' noted that pandemics cause vast human suffering and devastating economic costs. The World Bank believe that when an infectious disease outbreak occurs, health systems come under enormous pressure, and other health objectives are often compromised, as resources are diverted to contain the outbreak and patients avoid seeking care.

Pandemic therefore causes pressure and fear especially when it comes as a daily reports from the mass media. It is therefore important to look at this subject of panic reporting during public health risk.

\section{Justification and Objective}

Media organizations, as Dong and Zheng (2020) noted, play an important role in the dissemination of news pertaining to public health crises, and media coverage has a direct or indirect impact on public behaviours. Public panic during outbreaks of disease could be attributed to the manner of media coverage or the nature of the disease. The study therefore among other things will contribute to the existing concepts, theories and studies on panic reporting during disease outbreak. This study in a broader perspective is part of the field of health communication. Specifically, the objective of the study among other things centred on:

1. Determining public views on panic reporting and media framing on the Covid 19 pandemic.

\section{Theoretical Base}

The study is anchored on media framing. The concept of framing was posited by Gregory Bateson in 1972 (Arowolo, 2017) and later by Goffman in 1974, as 'Frame Analysis' (Dorfman, \& Krasnow, 2014). According to Arowolo (2017), framing describes the practice of thinking about news items and story content within familiar context. Because the notion of framing has been increasingly central to media analysis (Shih, Wijaya, \& Brossard, 2008), it deals with how the media package and present information to the audience or how audiences feel about an issue (Gamson \& Modigliani, 1989).

Framing is an expansion of the agenda-setting postulation by focusing on the essence of the issues at hand rather than on a particular topic. In fact, media farming is an extension of agenda-setting theory. While agendasetting deals with what the reporter and editor as gate-keepers, media framing looks at all the angles of the news presented, time of the news, the degree of discussion given to the news, salient areas invoked, and the prominence given to the news. It is indeed, how the news is framed. The basis of framing theory is that the media focuses attention on certain events and then places them within a field of meaning. According to Dorfman and Krasnow (2014), framing is the process of reconciling new information with one's existing understanding. Journalists in media framing decide which facts, values and perspectives will be given prominence. This means that reporters certainly apply their own perspectives and interpretative frames when packaging news. Media framing is journalist narratives.

Shih, Wijaya, \& Brossard (2008) have looked at the implications of media framing on newspapers (New York Times) coverage of epidemics on audience. They found that media framing of epidemic news changes attitude towards health behaviour. Media framings on the outbreak of the Covid 19 were outlined on numbers of death; number of affected persons; preventive measures; causes; the degree to which the virus spread, and the consistent media reportage. All these were capable of creating public panic and uncertainties. The table below explains media framing during public health risk. 
TABLE 1 A Framing Typology for Media Coverage of Epidemic Diseases

Frames
Consequence
The consequences of the diseases, such as human life (victims), social impact, or economic
impact (cost), are the focus of the story. In addition to damages, it also includes any
phenomenon, social/ political issues, events, or discussion generated by the occurrence
or spread of diseases. For example, the discussion of flu vaccine or drugs, although
indirect, is considered as a consequence of avian flu because the "talk" derives from the
potential outbreak of the flu.
This frame is characterized by uncertainties in any aspect(s) of the epidemics including the
cause, the cure, the possible spread, etc. Also included is portrayal of the disease as
something unknown that is in need of more exploration or examination by the experts or
governments.
The story stresses any action(s) against the disease, including prevention,
potential solutions, or strategies. The ban public gathering is one
example.
The story expresses the idea that the public should not be worried about the effects of the
disease. Stories that emphasize the readiness and/or successes of authorities in
combating the disease are also included.
Reassurance $\quad$ The story focuses on the difference in opinions as well as outright arguments/disagreements among
news sources. It could be a debate about how to effectively combat the diseases,
disagreement about how diseases will evolve and how serious it will affect people, or
dispute over the appropriateness or legitimacy of actions. Conflict story is constructed
as antagonism between opposing opinions or stances
This frame refers to new findings/ results of research efforts or discovery of new evidence
that help advance the understanding of the diseases or the ability to quell the diseases.
Included in this frame are: discovery of new strains of the disease, new way of
spreading/ transmitting, new methods to prevent/cure/treat the disease, development of
new medicine, and so on.

Source: Shih, Wijaya, \& Brossard (2008).

The work of Shih, Wijaya, and Brossard (2008) showed the manner of media framing during pandemics. Elements of fears, uncertainties, effects or consequences (economic, health social and emotional), reassurance and divergent views or conflict, actions or steps taken by the governments were the items that dominated media framing as shown in the table. This implies that media framing as, Gamson and Modigliani (1989) noted, is media package and presentation of information to the audience or how audiences feel about an issue.

The theory of media framing on panic reporting on public health risk looks at how the media focuses attention on certain important parts of the pandemic by looking at all the angles of the news presented, the degree of discussion given to the news, salient areas invoked or the prominence given to the news, the degree or level of public risk, the impacts the news generated, and the preventives measures.

\section{Methods and Procedures}

The research was concerned with young and older adults. The design was survey in nature. Participants were from the ages between 17-50, and above. Based on a cross-sectional study, the participants were randomly drawn from a University and a local government council secretariat in Oghara town, Delta State, Nigeria. Participants drawn from school were students in their final degree programme from Western Delta University, Oghara, Delta State, Nigeria. Participants from the government offices were from Ethiope West Local Government Council Secretariat. Due to the Covid 19 regulation of social distancing, only thirty four (34) participants were reached. This was in the month of September, 2020.

A structured format was developed to collect data. Questionnaire was the instrument for data collection. The objective of the instrument for data collection was to ascertain public views on panic reporting from media framing during the pandemics. Since schools were shutdown during the Covid 19 pandemic, questionnaire was sent to the students via emails. Thirteen (13) students were emailed with the questionnaire. Therefore, a total of 34 participants were contacted. Thirteen (13) were contacted via emails while twenty-one (21) civil servants from the Ethiope West Local Government Council Secretariat were reached on one-one-contact. Strict compliance to Covid 19 regulations like wearing of nose mask and hand sanitizing were adhered to during the administration of the questionnaire. All the participants responded to the questionnaire. The overall response rate was $100 \%$ based on the number of copies of the questionnaire provided and responded to. 


\section{Measuring Scale}

To measure public views on panic reporting from media framing during pandemics, three measuring scales were designed. The Likert Scale was used in table 1 and table 5 to measure participants' views on panic reporting and media framing during pandemics. The response pattern of this scale was a $5-1$ point $(5=$ I strong agree; $4=\mathrm{I}$ agree; 3 = 1 undecided; $2=1$ strongly disagree and $1=1$ disagree). This 5 point scaling technique had been used by Keshvari and collogues (2018) in measuring health reporting status and challenges among journalists. Table 2 rated public views on panic reporting from health risk coverage. The table was designed in a 3 scale response pattern of High, Medium and Low. This type of measuring scale has been used by Suckling, Ferris, and Price (2020) in assessing risk identification and management in public health practice. How media reports on the Covid 19 affect participants emotionally was measured by two scale of Yes or No option in table 3. Table 4 ascertained respondents' main medium or source of the media reports. The Yes or No option was used.

Contents or items in the research instrument were drawn from reading online newspapers and social media posts, watching television and listening to radio during the lockdown. This aided the investigator to design the research instrument. Data obtained were analysed in percentage and mean

\section{Results}

\section{Table 1: Public Views on Panic Reporting and Media framing During Pandemics}

\section{$\mathbf{S} / \mathbf{N} \quad$ Items}

1. Media coverage on pandemics aggravates public fears

2. Media reports and framing of pandemics outbreak caused more fears and anxieties than the virus.

3. The media reported it the way they saw it.

4. Media report on the pandemic caused panic buying

5. Media coverage reduces the spread of the virus.

6. The reporting on the numbers of death and infected cases made the public to panic the more.

7. Government directives for the public to follow simple safety instructions on the pandemic helped to reduce public panic and the spread of the virus.

8. Media coverage on the pandemic made the government lockdown regulations effective

9. The outbreak of the pandemic exposed government failed health system in Nigeria

10. Responsible and recommended health attitude and practices were the best factors that ease panics than media reports.

Respondents' expressed their views on pandemic reporting as framed by the media on a set mean at 3.00

$\begin{array}{cccccl}\text { SA } & \text { A } & \text { UD } & \text { SD } & \text { D } & \text { Mean } \\ 14 & 10 & 1 & 2 & 7 & 3.70 \\ 7 & 17 & - & 3 & 7 & 3.41 \\ 7 & 21 & 1 & 4 & 1 & 3.85 \\ 5 & 19 & 1 & 3 & 6 & 3.41 \\ 14 & 10 & 1 & 3 & 6 & 3.67 \\ 11 & 23 & - & - & - & 4.32 \\ & & & & & \\ 3 & 6 & - & 6 & 19 & 2.05 \\ & & & & & \\ 8 & 15 & 1 & 2 & 8 & 3.38 \\ 21 & 3 & - & - & - & 3.44 \\ 11 & 14 & - & - & 9 & 3.52\end{array}$

Table 2: Rating of Public Views on Panic Reporting from Health Risk Coverage Rate your views on panic reporting from health risk coverage by the mass media. Please Tick ONE ONLY Options

1. Panic caused by media reportage was......

2. Likelihood of public health risk by media framing was........

High

Medium Low

Media reports on the virus were.........

Panic buying caused by media reports was.......

18
17

17

29

20

25

16

18

17

$\begin{array}{cc}10 & 6 \\ 11 & 6 \\ 5 & - \\ 14 & - \\ 7 & 2 \\ 14 & 4 \\ 12 & 2 \\ 6 & 12\end{array}$


Table 3: Psycho-Emotional Analysis

Please indicate how media reports on the COVID 19 affect you emotionally. Tick ONE ONLY

$$
\text { Options }
$$

1. Had sleep problem at the start of the pandemic news

Yes

I became restless

3. I had fears and anxieties

4. My blood pressure got increased

5. Had depression

I became worried because of my financial situation

7. Was angry

8. Loss weight

9. I was afraid to go out to see others

10 I became suspicious of everybody

11. I became sick as a result of fear

$\begin{array}{cccc}\text { Yes } & \text { \% } & \text { No } & \text { \% } \\ 28 & 82.3 & 6 & 1.8 \\ 12 & 35.3 & 22 & 64.7 \\ 21 & 61.7 & 13 & 38.2 \\ 9 & 26.4 & 25 & 73.5 \\ 11 & 32.4 & 23 & 67.6 \\ 28 & 82.3 & 6 & 1.8 \\ 24 & 70.5 & 10 & 29.4 \\ 14 & 41.1 & 20 & 58.8 \\ 24 & 70.5 & 10 & 29.4 \\ 19 & 55.8 & 15 & 44.1 \\ 11 & 32.4 & 23 & 67.6\end{array}$

Table 4: Main Source of Reports on Panic Reporting Which one of these media is the most source of panic reporting to you?

\section{Options}

Yes (\%)

9 (26.4)

$11(32.3)$

$2(5.88)$

$7(20.5)$

$3(8.82)$

$2(5.88)$
No

Newspapers

Health officials in the hospitals

Interactions with friends

Table 5: Indication of Media Framing

Indicate how the media frame the pandemic report within certain periods

$\begin{array}{llcccccc}\text { S/N } & \text { Framed items } & \text { SA } & \text { A } & \text { UD } & \text { D } & \text { SD } & \text { Mean } \\ \text { 1. } & \text { Fear/panic } & 28 & 6 & - & - & - & 4.82 \\ \text { 2. } & \text { Uncertainty } & 26 & 8 & - & - & - & 4.76 \\ \text { 3. } & \text { Reassurance } & 20 & 13 & - & - & - & 4.47 \\ \text { 4. } & \text { Mild } & - & - & - & 25 & 9 & 1.73 \\ \text { 5. } & \text { Conflict } & 23 & 11 & - & - & - & 4.67 \\ \text { 6. } & \text { Preventive } & 17 & 9 & - & 8 & - & 3.55 \\ \text { 7. } & \text { Consequence/Effect } & 16 & 11 & - & 7 & - & 4.26 \\ \text { 8. } & \text { Difficult situation } & - & - & - & 27 & 7 & 1.79 \\ \text { 9. } & \text { Anxieties } & 14 & 20 & - & - & - & 4.41 \\ 10 . & \text { Depressive } & 14 & 9 & - & 9 & 2 & 4.29\end{array}$

\section{DISCUSSION}

The main objective of the study was to determine public views on panic reporting during the Covid 19 pandemic. On table one, respondents' expressed their views on pandemic reporting as framed by the media. Where all calculated mean from items 1 to 4 were greater than set mean (3.00), the respondents' indicated that media framing and coverage on the pandemic aggravated public fears, as it causes more fears and anxieties than the virus itself. However, the respondents believed that media reported the pandemic the way they saw it $(3.85>$ 3.00). On this, Cappella and Jamieson (1997) believe that in public health risk reporting, there is journalistic tendency to draw attention to certain features of an issue while minimizing attention to others. The media frames become 'journalist narratives'. This is why media framing is an extension of the gatekeeping postulation. Though media coverage and framing of the pandemic news increases public panic, it however reduces the spread of the virus, as the panic made respondents to follow safety instructions. This was agreed at a point where arrived or calculated mean $(3.67>3.00)$. Also, at a arrived mean at $4.32>3.00$, it was taken that reports on the numbers of death and infected cases increased public panic. The respondents' however rejected the assumption that the government directives for the public to follow simple safety instructions on the pandemic helped to reduce public panic. This implies that the safety instructions on the pandemic like social distancing, wearing of face mask and regular washing of hands did not help to reduce public panic but the spread of the virus. Management of news during public health risk or crisis is important for easing panic. On the other hand, media coverage on the pandemic made the government lockdown regulations effective (where $3.38>3.00$ ). In the same vein, at a point $3.44>3.00$, it was discovered that the outbreak of the pandemic exposes government failed 
health system in Nigeria. The various governments since independence in 1960 do not have any solid and reliable health plans, scheme or system. This is why many fly abroad for medical treatment. The health system is a complete failure, and this has made so many medical practitioners to go abroad to practice.

In furtherance to the findings discussed above, rating of the respondents' views on panic reporting from health risk coverage by the mass media was also ascertained. The rating scale of high, medium and low scales were provided. The results showed that panic caused by media reportage on public health risk by media framing were high. The high rate of reporting or coverage on the pandemic by the mass media with high adverse economic effects on the public caused by government lockdown regulations led to high rate of panic buying of food items. Media reports on the pandemic also brought high public attention to media news especially the broadcast media, in a manner that many people wants to know the latest development as regards the Covid 19. The broadcast media have been held in high esteem as a result of its attention-getting features of sounds and images (for television) which makes it emotional. Result in table 4 corresponds with the findings that television medium was the major source of information about the pandemic to the respondents. The public holds the media in high esteem (McQuail, 2010). As it were, heavy dependency and exposure to the media tend to shape people's beliefs and perceptions about various issues of life. Aptly put, the degree of dependency on the media explains why audience's beliefs, feelings or behaviours are affected by media contents. It is imperative to know that the degree to which the broadcast media devote air time to the Covid 19 determines people's attitudes to safety instructions. This is why Haas, Kaplan, Gerstenberger, and Kerlikowske (2004) posit that the influence of media on public beliefs is so huge that sometimes people adopt a new treatment due to the latest health news they learn about through the media.

Panic reporting especially on health affects the public emotionally. Dong and Zheng (2020) noted 'psychological disorder caused by too many news coverage'. The results on emotional effects of panic reporting showed that $82.3 \%$ of the respondents experienced sleeping problem at the start of the pandemic news along with fear and anxieties caused by the extent of media reportage on the virus. Fear made everyone suspicious of other person, and this made it difficult to go out to see others. Media report on the pandemic not only increases panics but also causes financial worries. This was indicated by $76.4 \%$ of the respondents. All the results point to fear. Wahl-Jorgensen (2020) believes that fear has been a strong causal factor of pandemic death.

It is imperative to know from the respondents how the media framed the pandemic report within certain periods especially the earliest period of March to May, and then later June to August and September, 2020. Options were provided for the respondents' to ascertain how the media framed the pandemic reports. Results showed that at the beginning of the pandemic in Nigeria, the news media airwaves were dominated by fear, uncertainty, anxieties, panic buying, worries, deaths but later there were level of reassurance through preventive measures, mildness, and the application of responsible health attitude.

In all, the study showed that media framing and coverage of the pandemic news increases public panic, but it however reduces the spread of the virus because of fear associated with the news. Media rate of reportage on the pandemic was high. The high rate of the reportage on the pandemic by the mass media with high adverse economic effects on the public caused by government lockdown regulations led to high rate of panic buying. This was because the pandemic news was not carefully managed by the media. The news was too direct like a straight bullet without considering the psychological or emotional effects on some members of the public. The study also showed that the outbreak of the pandemic exposes government failed health system in Nigeria. It was established that self responsible attitude was the best factor that ease panics not media reports and the lockdowns.

\section{CONCLUSION}

Health crisis attracts the attentions of the public as well as the mass media. In reporting on public health risk, the news media are capable of causing public panic depending on variable factors namely the nature of the diseases and the manner of media coverage or extent of reportage. In this study, public views on panic reports and media framing of pandemics were ascertained. The public viewed media reports and manner of framing as a major cause of public panic not the virus itself. The news coverage on the virus was too direct without considering the psychological or emotional effects on some members of the public. Public panic caused by media reportage on the virus also led to panic buying of food items at home. Though the media reported the story of the Covid 19 the way they saw it but management of news during public health risk or crisis is important for easing panic It was established that responsible health attitude or practice as recommended is most appropriate to ease panics.

\section{REFERENCES}

Akpoghiran, I.P \& Otite, E.S. (2013). Television news perspective of conflict reporting: The Nigerian Television Authority as a reference point. Journal of Media and Communication Studies. 5(2), 12-19. Available in www.academicjournals.org/JMCS

Arowolo, S.O. (2017). Understanding framing theory. ResearchGate publication. Retrieved $7^{\text {th }}$ March, 2020.

Batelaan, N.M; Seldenrijk, A; Bot, M, Balkom, A.J.L.M; Penninx, B.W.J.H. (2016). Anxiety and new onset of 
cardiovascular disease: critical review and meta-analysis. Br J Psychiatry. 208:223-231.

Brinn, M. P; Carson, K. V; Esterman, A. J; Chang, A. B \& Smith, B. J. (2012). Mass media interventions for preventing smoking in young people. Cochrane Database of Systematic Reviews, vol. 11, ID CD001006, 2010.

Cappella,J.N.,\&Jamieson,K.H.(1997).Thespiralofcynicism:Thepressandthepublicgood.NewＹYork: Oxford University Press.

Collinson, S. L \& Heffernan, J. M. (2014). Modeling the effects of media during an influenza epidemic. BMC Public Health 14:376 http://www.biomedcentral.com/1471-2458/14/376

Dorfman, L \& Krasnow, I.D. (2014). Public health and media advocacy. Annual Review of Public Health publication. 35, 293-306. www.annualreviews.org. Retrieved $7^{\text {th }}$ April, 2020.

Dong, M \& Zheng, J. (2020). Letter to the editor: Headline stress disorder caused by Netnews during the outbreak of COVID-19. Wiley publication. DOI: 10.1111/hex.13055

Gamson, W., \& Modigliani, A. (1989). Media discourse and public opinion on nuclear power: A constructionist approach. American Journal of Sociology, 95, 1-37.

Haas, J.S; Kaplan, C.P; Gerstenberger, E. P; Kerlikowske; K. (2004). Changes in the use of postmenopausal hormone therapy after the publication of clinical trial results. Ann Intern Med 140:184 8 .

Keshvari,M; Niko Yamani,N; Adibi, P; \& Shahnazi, H. (2018). Health Journalism: Health Reporting Status and Challenges. Iranian Journal of Nursing and Midwifery Research. 23 (1), 14-17.

Liu M.Y; Li NA, Li WA; Khan, H. (2017). Association between psychosocial stress and hypertension: a systematic review and meta-analysis. Neurol Res. 2017;39:573-580.

McCauley, M. P; Blake, K.D; Meissner, H; Viswanath, K. (2013). The social group influences of US health journalists and their impact on the news making process. Health Educ Res: 28: 33951.

McCombs, M. (2013). Setting the agenda: The mass media and public opinion. John Wiley \& Sons.

McQuail, D. (2010). McQuail's mass communication theory. ( $\left.6^{\text {th }} \mathrm{ed}\right)$. London: SAGE Publications.

Shih, T.J; Wijaya, R; \& Brossard, D. (2008). Media Coverage of Public Health Epidemics: Linking Framing and Issue Attention Cycle Toward an Integrated Theory of Print News Coverage of Epidemics. Journal of Mass Communication \& Society, 11:141-160. Routledge. DOI: 10.1080/15205430701668121

Suckling, R., Ferris, M. \& Price, C. (2020). .Risk identification, assessment and management in public health practice: a practical approach in one public health department. Journal of Public Health Medicine. 25 (2), 138-143. DOI: 10.1093.

Tchuenche, J.M \& Bauch, C.T. (2012). Dynamics of an Infectious Disease Where Media Coverage Influences Transmission. doi:10.5402/2012/581274

Viswanath, K; Ramanadhan, S; Kontos, E.Z. (2007). Mass media in macro-social determinants of population health. Springer; 275-294.

Wahl-Jorgensen, K. (2020). Coronavirus: how media coverage of epidemics often stokes fear and panic. Published by Cardiff University, Australia and The Conversation Africa, Inc

WHO (2009). An Introduction to Risk Communication. WHO Communications working group report March 2009

World Bank (2017). From Panic and Neglect to Investing in Health Security: Financing Pandemic Preparedness at a National Level. A Report by the International Working Group on Financing Preparedness for Pandemic. 